\title{
Diffusion-weighted magnetic resonance imaging may identify candidates for alternatives to lobectomy for early stage lung cancer
}

\author{
Jeffrey A. Hagen, MD
}

See related article on pages 991-6.

In the evaluation of patients with known or suspected lung cancer, current practice for most thoracic surgeons is to perform computed tomographic scanning, usually combined with positron emission tomographic imaging. Magnetic resonance imaging (MRI), if used at all, is relegated to evaluation of the brain and occasionally the adrenal glands in select patients. As technology evolves, however, we would be wise as thoracic surgeons to "stay in touch" with developments in MRI, as there are increasing data documenting its utility in many areas of lung cancer management.

MRI with diffusion weighting (DW) has been shown to be of value in assessing mediastinal nodes, with studies showing negative predictive values that rival positron emission tomographic imaging (as high as $94 \%$ ). ${ }^{1}$ MRI with DW has also been shown have relatively high accuracy and a high specificity in excluding malignancy in patients with a solitary pulmonary nodule. ${ }^{2}$ The ability of MRI with DW to identify areas of high cellularity has also led to its use in the more accurate guidance of percutaneous needle biopsies ${ }^{3}$ and prediction of response to stereotactic body radiotherapy. ${ }^{4}$ In some centers, MRI is also being used in combination with positron emission tomographic imaging, eliminating the radiation exposure from the attenuation-correction computed tomographic scan.

The results of the study by Nomori and colleagues ${ }^{5}$ published in this issue of the Journal of Thoracic and Cardiovascular Surgery may well add another very important reason to consider MR imaging as part of the management of patients with lung cancer. In a study of 145 patients with early stage lung cancer, they performed MRI with DW, visually classifying the patterns as homogeneous and heterogeneous and further classifying the former as faint or dark according to the signal intensity. In all, just less than $20 \%$ of the tumors

\footnotetext{
From the Division of Thoracic Surgery, Keck School of Medicine, University of Southern California, Los Angeles, Calif.

Disclosures: Author has nothing to disclose with regard to commercial support. Received for publication Feb 10, 2015; accepted for publication Feb 12, 2015.

Address for reprints: Jeffrey A. Hagen, MD, Department of Surgery-CT Division, University of Southern California, 1510 San Pablo St, Suite 514, Los Angeles,

CA 90033 (E-mail: hagen@hsc.usc.edu).

J Thorac Cardiovasc Surg 2015;149:997

$0022-5223 / \$ 36.00$

Copyright (C) 2015 by The American Association for Thoracic Surgery http://dx.doi.org/10.1016/j.jtcvs.2015.02.051
}

were classified as having the faint homogenous pattern, representing a group of patients who universally had welldifferentiated adenocarcinomas, mostly T1a, and no evidence of pleural invasion or lymph node involvement.

The significance of their findings lies in the current explosion of interest in alternatives to anatomic lobectomy in patients with small peripheral lung cancers. With widespread application of computed tomographic screening protocols and the shift in histologic type from squamous cell to adenocarcinoma that has been occurring, the numbers of these patients will likely increase substantially in the coming years. Alternative approaches to the traditional lobectomy and node dissection include video-assisted thoracoscopic surgery with sublobar resection and, perhaps more notably, stereotactic body radiotherapy and thermal ablation techniques. The Achilles' heel of these approaches is the inability to date to address fully the potentially involved nodes. The frequency of clinically occult nodal disease in stage 1 lung cancer has been estimated between $15 \%$ and $20 \%{ }^{6,7}(19 \%$ in the series of Nomori and colleagues), and this has been used as justification for continued performance of the criterion standard lobectomy approach. This may change, however, if a reliable means of predicting the absence of node involvement can be proved. The study by Nomori and colleagues may be an important step in this direction.

\section{References}

1. Xu L, Tian J, Liu Y, Li C. Accuracy of diffusion-weighted (DW) MRI with background signal suppression (MR-DWIBS) in diagnosis of mediastinal lymph node metastasis of nonsmall-cell lung cancer (NSCLC). J Magn Reson Imaging. 2014; 40:200-5.

2. Koyama H, Ohno Y, Seki S, Nishio M, Yoshikawa T, Matsumoto S, et al Value of diffusion-weighted MR imaging using various parameters for assessment and characterization of solitary pulmonary nodules. Eur J Radiol. 2015; 84:509-15.

3. Guimarães MD, Hochhegger B, Benveniste MF, Odisio BC, Gross JL, Zurstrassen CE, et al. Improving CT-guided transthoracic biopsy of mediastinal lesions by diffusion-weighted magnetic resonance imaging. Clinics (Sao Paulo). 2014;69:787-91.

4. Iizuka Y, Matsuo Y, Umeoka S, Nakamoto Y, Ueki N, Mizowaki T, et al. Prediction of clinical outcome after stereotactic body radiotherapy for non-small cell lung cancer using diffusion-weighted MRI and ${ }^{18}$ F-FDG PET. Eur J Radiol. 2014;83: 2087-92.

5. Nomori H, Cong Y, Abe M, Sugimura H, Kato Y. Diffusion-weighted magnetic resonance imaging in preoperative assessment of non-small cell lung cancer. J Thorac Cardiovasc Surg. 2015;149:991-6.

6. Takizawa T, Terashima M, Koike T, Watanabe T, Kurita Y, Yokoyama A, et al. Lymph node metastastasis in small peripheral adenocarcinoma of the lung. $J$ Thorac Cardiovasc Surg. 1998;116:276-80.

7. Asamura H, Nakayama H, Kondo H, Tsuchiya R, Shimosato Y, Naruke T. Lymph node involvement, recurrence and prognosis in resected small peripheral nonsmall-cell lung carcinomas: are these carcinomas candidates for video-assisted lobectomy? J Thorac Cardiovasc Surg. 1996;111:1125-34. 